\title{
Evaluation of Thermodynamic Parameters of 2, 4-Dichlorophenoxyacetic Acid (2, 4-D) Adsorption
}

\author{
A. S. Ghatbandhe, ${ }^{1}$ H. G. Jahagirdar, ${ }^{1}$ M. K. N. Yenkie, ${ }^{2}$ and S. D. Deosarkar ${ }^{3}$ \\ ${ }^{1}$ Department of Chemistry, SFS College, RTM Nagpur University, Nagpur 440006, India \\ ${ }^{2}$ Department of Chemical Technology, Laxminarayan Institute of Technology, RTM Nagpur University, Nagpur 440033, India \\ ${ }^{3}$ School of Chemical Sciences, SRTM University, Nanded 431606, India
}

Correspondence should be addressed to A. S. Ghatbandhe; ajay_gbandhe@rediffmail.com

Received 13 June 2012; Accepted 5 October 2012

Academic Editor: J. Morillo Aguado

Copyright (C) 2013 A. S. Ghatbandhe et al. This is an open access article distributed under the Creative Commons Attribution License, which permits unrestricted use, distribution, and reproduction in any medium, provided the original work is properly cited.

\begin{abstract}
Thermodynamic parameters of 2, 4-Dichlorophenoxyacetic acid (2, 4-D) adsorption were evaluated by studying the adsorption equilibrium and kinetics of 2, 4-D at different temperatures. Uptake capacity of activated carbon increases with temperature. Langmuir isotherm models were applied to experimental data of 2, 4-D adsorption. Equilibrium data fitted very well to the Langmuir equilibrium model. Adsorbent monolayer capacity $\mathrm{Q}^{0}$, Langmuir constant $a$ and adsorption rate constant $k_{a}$ were evaluated at different temperatures for activated carbon adsorption. The activation energy of adsorption $\left(E_{a}\right)$ was determined using the Arrhenius equation. Using the thermodynamic equilibrium coefficients obtained at different temperatures, the thermodynamic constants of adsorption $\left(\Delta G^{0}, \Delta H^{0}\right.$, and $\left.\Delta S^{0}\right)$ were evaluated. The obtained values of thermodynamic parameters show that the adsorption of 2, 4-D is an endothermic process.
\end{abstract}

\section{Introduction}

Along with industrial activities, agricultural activities also contribute in water pollution to the greater extent. Hence wastewater without an efficient treatment is becoming a serious problem. Among the numerous agrochemicals in use today, the herbicide 2, 4-D has been widely applied to control broad-leaved weeds in gardens and farming. Consequently, it has been frequently detected in water bodies in various regions of the world. The adsorption process is one of the efficient methods to remove organics from effluent [1, 2]. Activated carbons have also been employed to remove organic contaminants from wastewater and gaseous wastes [3-5]. Electrostatic and van der Waals forces, H-binding, dipole-dipole interactions, ion exchange, covalent bonding, cation bridging, and water bridging can be responsible for the adsorption of organic compounds on activated carbon [613]. It is reported that the pore size of the activated carbons significantly influence the adsorption capacity of natural organic materials subject to their molecular sizes [14]. Several researchers studying dye adsorption on activated carbon $[15,16]$ have pointed out that the presence of mesopores together with micropores in the activated carbon enhances their adsorption capacities, especially, for large adsorbates $[17,18]$. These reports suggest that the pore size distributions of activated carbons decide their proper applications.

Generally an elevated temperature provides faster rate of diffusion of adsorbate molecules through the solution to the adsorbent surface and into adsorbent. Zogoroski $[4,5]$ obtained the adsorption isotherm for phenol at different temperatures and concluded that adsorption decreases with the increase in temperature and concluded that adsorption is an exothermic process. On the contrary Tütem et. al. [19] concluded that the adsorption of chlorophenols from aqueous phase on bituminous shale was endothermic and basically of physical character. The equilibrium uptake of 2 , $4-D$ by GAC was also affected by temperature and increases with increasing temperature [20].

In the present investigation, equilibrium and kinetics studies of adsorption of 2, 4-Dichlorophenoxyacetic acid (2, 
4-D) from aqueous solution on granular activated carbon has been carried out at five different temperatures to evaluate thermodynamic parameters. The adsorption equilibrium data for the adsorbate-adsorbent systems studied were expressed by Langmuir isotherm model and a simplified rate expression based on Langmuir adsorption theory was used to evaluate the adsorption " $k_{a}$ " and desorption " $k_{d}$ " rate constants. This data was then used to calculate the energy of activation of adsorption and desorption also the thermodynamic parameters, namely, the free energy of adsorption " $\Delta G^{0}$ ", enthalpy of adsorption " $\Delta H^{0}$ ", and the entropy of adsorption " $\Delta S^{0}$ ".

\section{Materials and Methods}

2.1. Materials. In the present investigation commercially available granular activated carbon (GAC), namely, Filtrasorb-400 (F-400) was used as adsorbent.

\subsection{Methods}

2.2.1. Adsorption Equilibrium Studies. A $500 \mathrm{~mL}$ round bottom flask containing $250 \mathrm{~mL}$ of distilled water was immersed in the thermostat bath. The content were constantly stirred at $800 \pm 50 \mathrm{RPM}$ and allowed to attain the temperature of the bath. After the temperature was reached, a calculated quantity of the stock solution was introduced into the distilled water with the help of graduated pipette. The solution was allowed to mix thoroughly and the same quantity of the resulting solution was pipetted out to maintain the final volume $250 \mathrm{~mL}$, which was then used for the determination of initial concentration. $0.25 \pm 0.001 \mathrm{~g}$ of the adsorbate sample was then introduced into the solution with the stirring speed at $800 \pm 50$ RPM. The time of addition of GAC was noted. Stirring was continued till the concentration of the aqueous phase showed no detectable change in UV absorbance. Preliminary experiments show that the adsorbate uptake profile was independent of stirring speed above $600 \mathrm{rpm}$ [21] and the equilibrium was attained in about 4 hours. As a precautionary measure, experiments were continued for five hours. Some of the experiments were carried out over a prolonged period of time where no significant difference was observed in the adsorbate concentration.

2.2.2. Adsorption Kinetics. For adsorption kinetics studies a 5-liter Borosil glass beaker fitted with six baffles was used. Three liters of experimental solution was prepared by adding appropriate amount of stock solution into boiled and cooled distilled water. $3.00 \pm 0.001 \mathrm{~g}$ of given GAC sample was introduced into the solution at a given instant of time. $5 \mathrm{~mL}$ of experimental solution was withdrawn at desired interval of time with the help of syringe and the concentration of adsorbate in the aqueous phase was estimated by UV analysis. Properties of adsorbent GAC F-400 and adsorbate used in the present study are given in Tables 1 and 2 respectively.

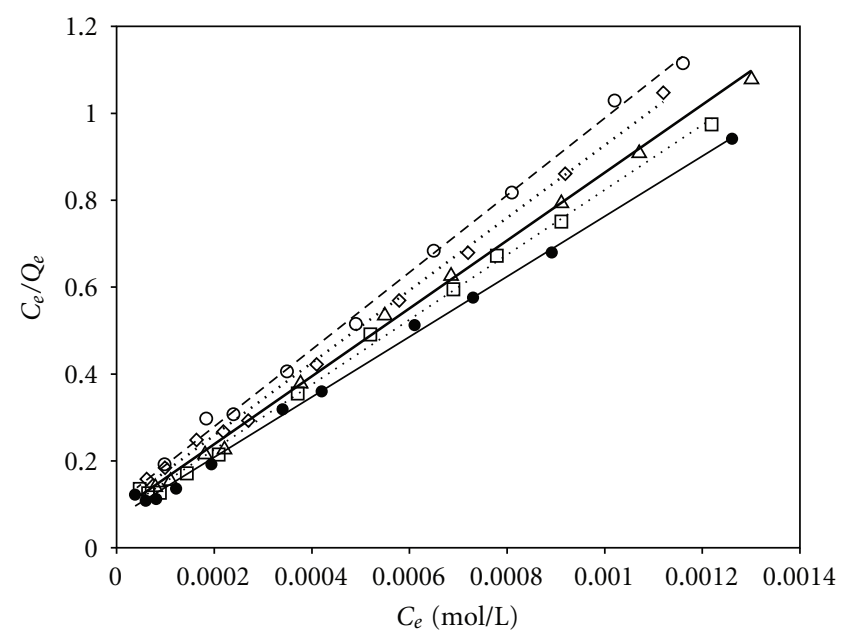

$$
\begin{aligned}
& \bigcirc 25^{\circ} \mathrm{C} y=887.12 x+0.1019 \quad \square 40^{\circ} \mathrm{C} y=746.63 x+0.0774 \\
& \diamond 30^{\circ} \mathrm{C} y=884.15 x+0.0925 \\
& \triangle 35^{\circ} \mathrm{C} y=781.22 x+0.0827
\end{aligned}
$$

FIGURE 1: Langmuir adsorption isotherms at different temperatures.

TABLE 1: Physico chemical properties of adsorbent Filtrasorb-400.

\begin{tabular}{lc}
\hline Properties & $\mathrm{F}-400$ \\
\hline $\mathrm{N}_{2}$-BET surface area & $998 \mathrm{~m}^{2} / \mathrm{g}$ \\
Particle density & $0.795 \mathrm{~g} / \mathrm{cm}^{3}$ \\
Pore volume & $0.825 \mathrm{~g} / \mathrm{cm}^{3}$ \\
Porosity & 0.65 \\
Phenol-BET surface area & $480 \mathrm{~m}^{2} / \mathrm{g}$ \\
Moisture & $1.9 \mathrm{wt} \%$ \\
Ash & $6.1 \mathrm{wt} \%$ \\
Volatile matter & $2.7 \mathrm{wt} \%$ \\
Fixed carbon & $89.3 \mathrm{wt} \%$ \\
Mineral matter & $6.71 \mathrm{wt} \%$ \\
\hline
\end{tabular}

\section{Result and Discussion}

The adsorption isotherms obeyed the Langmuir equation with a very high regression coefficient above 0.98 indicating a very good linear fit in all the cases. The Langmuir adsorption isotherm is represented by the following equation [21]:

$$
\frac{C e}{q e}=\frac{1}{Q^{0} b}+\frac{C e}{Q^{0}} .
$$

Langmuir isotherm plot at different temperatures is depicted in Figure 1. The plot also shows the Langmuir equation obtained by linear regression of the data.

The Langmuir isotherm characteristics can be expressed in terms of dimensionless constant separation factor $R_{L}$ [22] represented as

$$
R_{L}=\frac{1}{\left(1+b C_{0}\right)},
$$

where $b$ is the Langmuir constant and $C_{0}$ initial adsorbate concentration; $R_{L}$ values are given in Table 3 and indicate the 
TABle 2: Physico-chemical properties of adsorbate 2, 4-Dichlorophenoxyacetic acid (2, 4-D).

\begin{tabular}{lc}
\hline Mol. wt. & 221.0 \\
Water solubility $\mathrm{mol} / \mathrm{L}$ at $30^{\circ} \mathrm{C}$ & 0.00452 \\
$\lambda_{\max }(\mathrm{nm})$ & 282 \\
$\varepsilon\left(\mathrm{dm}^{3} \mathrm{~mol}^{-1} \mathrm{~cm}^{-1}\right)$ & 2057.1 \\
\hline
\end{tabular}

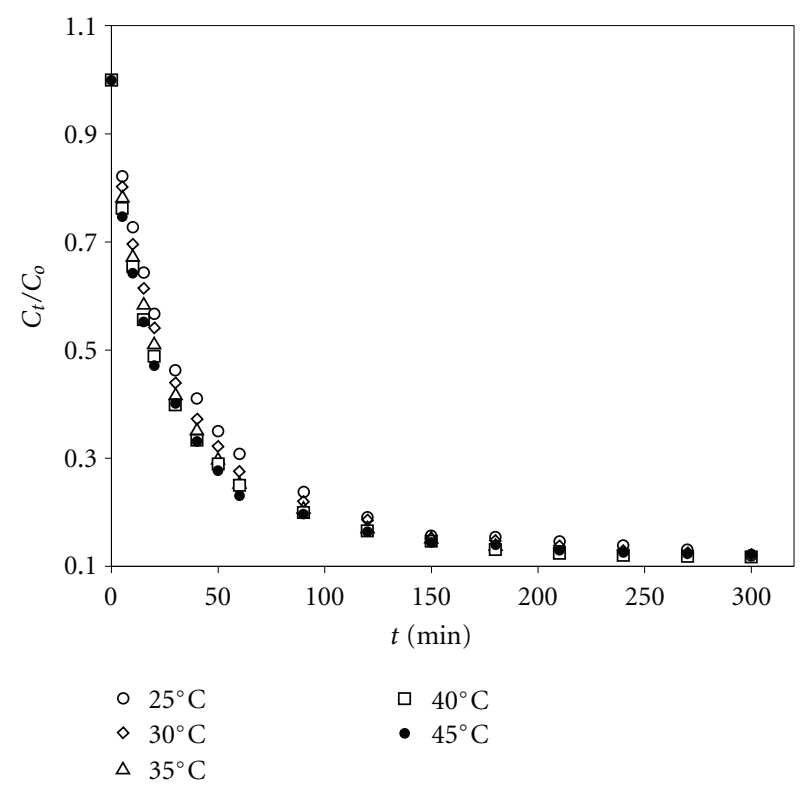

FIgURe 2: Adsorption kinetics of 2, 4-D at different temperatures.

type of isotherm. $R_{L}$ values between zero and one indicate favorable adsorption for $2,4-\mathrm{D}$ in the studied concentration range.

3.1. Adsorbate Removal Rate Studies. Adsorbate removal rate is expressed as a function of directly measurable fluid phase adsorbate concentration. Langmuir theory assumes that the rate of adsorption is proportional to the product of adsorbate concentration in fluid phase and the fraction of the vacant adsorbent surfaces. The fraction of the surface covered by the adsorbate, $Q$, will be proportional to the decrease in fluid phase adsorbate concentration, thus

$$
\begin{gathered}
\frac{d q}{d t}=k_{a} C_{t}(1-Q)-k_{d} Q, \\
Q=f\left(C_{0}-C_{t}\right),
\end{gathered}
$$

where, $k_{a}$ and $k_{d}$ are adsorption and desorption rate constants. $C_{0}, C_{t}$ and $C_{e}$, are the fluid phase adsorbate concentrations at time zero $t$ and at equilibrium, respectively; $f$ is proportionality constant. Substituting (4) in (3) and solving the resultant equation by applying the concept of steady state gives the final expression

$$
\ln \left[\frac{\left(C_{t}-C_{e}\right)}{\left(C_{t}+a\right)}\right]=-k_{a} C_{e} t+\ln \left[\frac{\left(C_{0}-C_{e}\right)}{\left(C_{0}+a\right)}\right],
$$

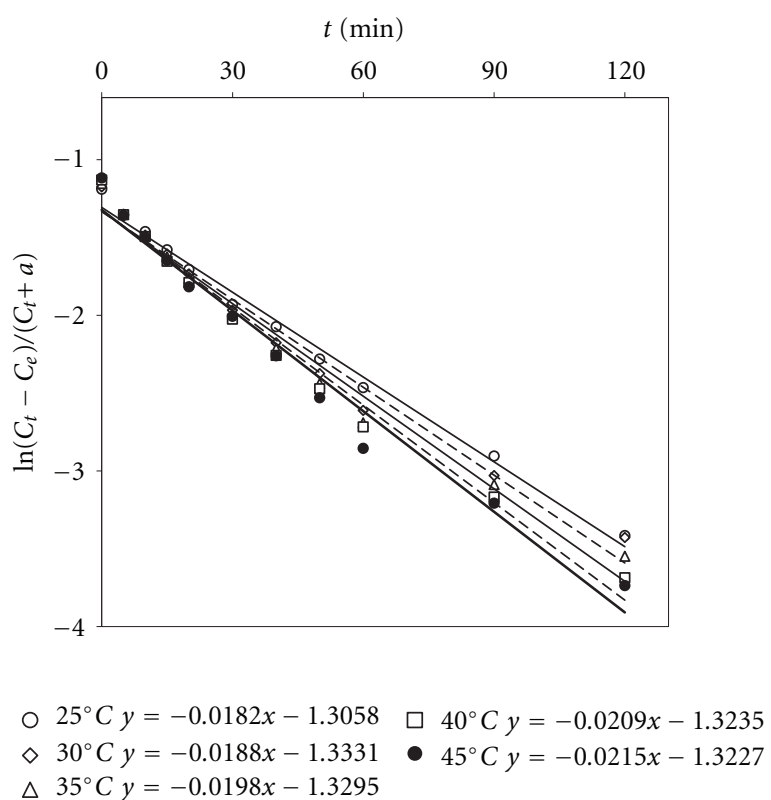

Figure 3: Adsorbate removal rate of 2, 4-D at different temperatures.

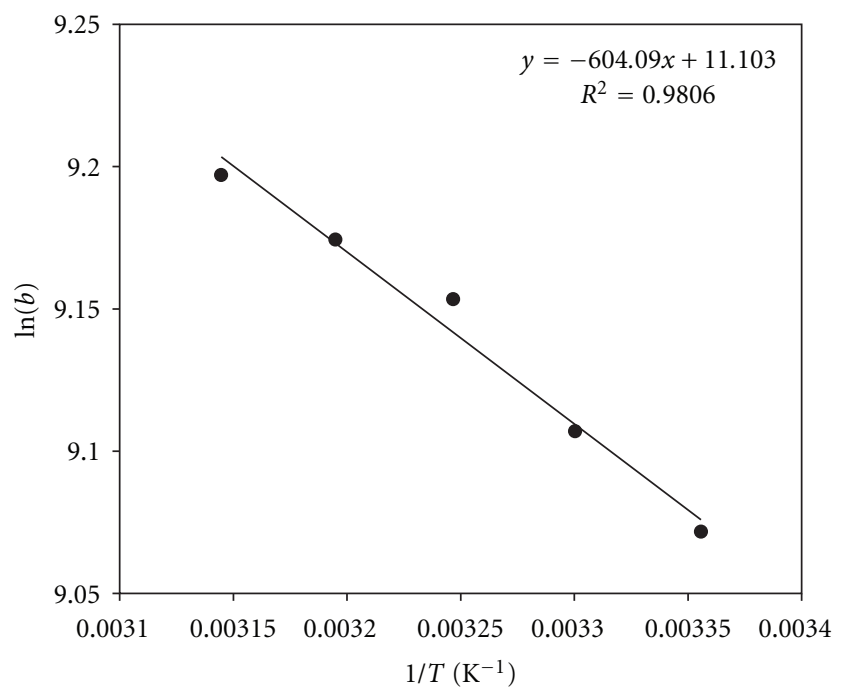

FIGURE 4: Vant Hoff plot for 2, 4-D adsorption at different temperatures.

where,

$$
a=\left(\frac{C_{0}}{b C_{e}}\right), \quad b=\frac{k_{a}}{k_{d}} .
$$

The adsorption " $k_{a}$ " and desorption " $k_{d}$ " rate constants were thus evaluated by plotting $\ln \left[\left(C_{t}-C_{e}\right) /\left(C_{t}+a\right)\right]$ against $t$. Figures 2 and 3 depict these plots for the adsorbate-adsorbent for all the studied temperatures in the present work. The plots also show the rate expressions obtained by linear regression analysis of the kinetic data.

The experimentally determined values of adsorbent monolayer capacity " $Q$ ", Langmuir constant " $b$ " for the adsorbate-adsorbent systems at all the five temperatures are 
TABLE 3: Effect of temperature on adsorption capacity and Langmuir constant.

\begin{tabular}{lccccc}
\hline$T, \mathrm{~K}$ & Slope & Intercept & $Q^{\circ} \times 10^{4}, \mathrm{~mol} / \mathrm{g}$ & $C_{e} \times 10^{4}, \mathrm{~mol} / \mathrm{L}$ & $b$ \\
\hline 298 & 887.12 & 0.1019 & 11.27 & $0.41-11.6$ & 8705.79 \\
303 & 834.15 & 0.0925 & 11.99 & $0.62-11.2$ & 0.187 \\
308 & 781.22 & 0.0827 & 12.80 & $0.48-13.0$ & 9017.84 \\
313 & 746.63 & 0.0774 & 13.39 & $0.49-12.2$ & 9446.43 \\
318 & 692.73 & 0.0702 & 14.44 & $0.38-12.6$ & 9646.38 \\
\hline
\end{tabular}

TABLE 4: Adsorption desorption rate constants and thermodynamic parameters of 2, 4-D adsorption.

\begin{tabular}{lccccc}
\hline$T$, & $\begin{array}{c}K_{a}, \\
\mathrm{~min}^{-1}\end{array}$ & $\begin{array}{c}K_{d}, \\
\mathrm{~min}^{-1}\end{array}$ & $\begin{array}{c}\Delta G^{0}, \\
\mathrm{~kJ} \mathrm{~mol}^{-1}\end{array}$ & $\begin{array}{c}\Delta H^{0}, \\
\mathrm{~kJ} \mathrm{~mol}^{-1}\end{array}$ & $\begin{array}{c}\Delta S^{0}, \\
\mathrm{JK}^{-1}\end{array}$ \\
\hline 298 & 298.36 & 0.0343 & -22.48 & & \\
303 & 313.33 & 0.0347 & -22.56 & & \\
308 & 335.59 & 0.0355 & -22.68 & 5.02 & 92.31 \\
313 & 348.33 & 0.0361 & -22.73 & & \\
318 & 358.33 & 0.0363 & -22.79 & & \\
\hline
\end{tabular}

summarized in Table 3. The adsorption and desorption rate constants obtained are given in Table 4.

3.2. Effect of Temperature. The results obtained in the present investigation are very informative. The equilibrium uptake of 2, 4-D by GAC is affected by temperature and increases with the rise in temperature. The adsorption desorption rate were found to decrease with the rise in temperature. The increase in the adsorption capacity with rise in temperature illustrates that 2, 4-D adsorption on to GAC F-400 is an endothermic process. The increase in the adsorption capacity of activated carbon at higher temperature may be attributed to the enlargement of pore size or activation of the adsorbent surface or creation of some new active sites on the surface of adsorbent due to bond rupture. This could also be due to the enhanced mobility of 2, 4-D ions from the bulk solution towards the adsorbent surface and extent of penetration within GAC structure overcoming the activation energy barrier and enhancing the rate of intraparticle diffusion [6, $23,24]$.

3.3. Thermodynamic Parameters. From the variation of $b$ (thermodynamic distribution coefficient or Langmuir constant) with temperature, thermodynamic parameters $\Delta G^{0}$, $\Delta H^{0}$, and $\Delta S^{0}$ namely, the standard free energy change, standard free enthalpy change, and standard free entropy change, respectively, were calculated using the following equations,

$$
\Delta G^{0}=-R T \ln b
$$

and Vant' Hoff equation,

$$
\ln b=\left(\frac{\Delta S^{0}}{R}\right)-\left(\frac{\Delta H^{0}}{R T}\right) .
$$

The Vant' Hoff plot of $\ln b$ against $1 / T$ was plotted (Figure 4) which shows an excellent linearity. $\Delta H^{0}$ and $\Delta S^{0}$ are

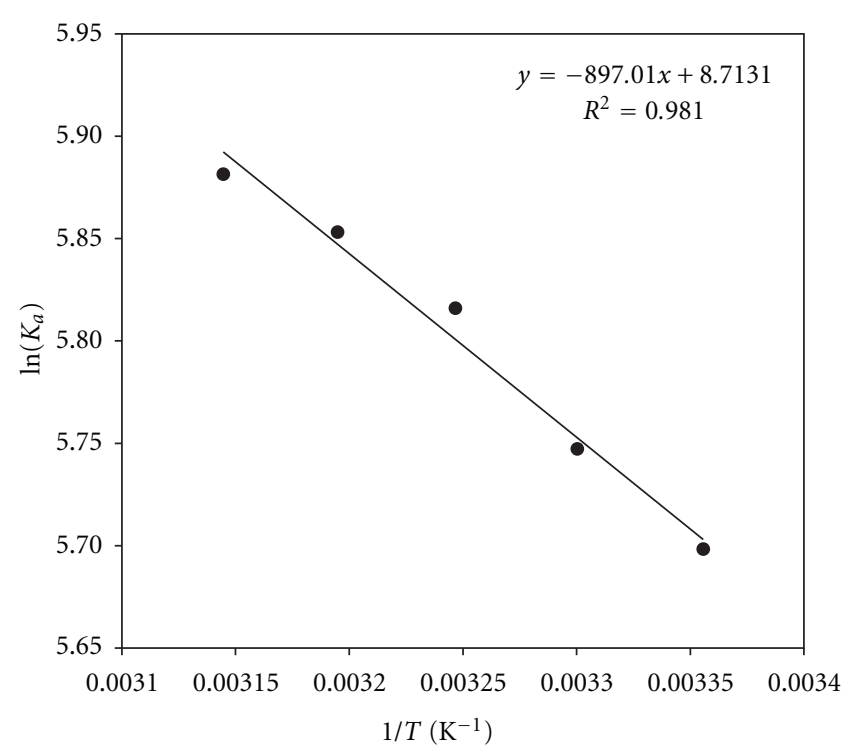

Figure 5: Plot of energy of activation of 2, 4-D adsorption.

obtained from slope and intercept of the plot and are given in Table 4 . The values of $\Delta G^{0}$ for all the studied temperatures are found to negative. The negative values of free energy are the indicative of spontaneous process with a high affinity of the adsorbate to the surface of adsorbent. The positive value of enthalpy change points the endothermic nature of adsorption process.

3.4. Energy of Activation of Adsorption. The activation energy of adsorption was determined using Arrhenius equation

$$
\ln k_{a}=-\left(\frac{E_{a}}{R T}\right)+\ln A .
$$

The plot of $\ln k_{a}$ versus $1 / T$ was plotted (Figure 5), and the linear regression analysis gave a linear regression coefficient above $0.980 . E_{a}$ value for the 2, 4-D-GAC system is given in Table 5.

\section{Conclusion}

(i) 2, 4-D adsorption using GAC is very rapid in the first hour of contact where $70 \%$ of the adsorbate is removed by GAC followed by a slow approach to equilibrium.

(ii) The Langmuir constant (b), related to the energy of adsorption, increased with temperature for all the 
TABLE 5: Effect of temperature on adsorption rate constants.

\begin{tabular}{lccc}
\hline$T, \mathrm{~K}$ & $k_{a}, \mathrm{~min}^{-1}$ & $E_{a}, \mathrm{~kJ} \mathrm{~mol}^{-1}$ & \% increase in $k_{a}$ \\
\hline 298 & 298.36 & & \\
303 & 313.33 & & 5.02 \\
308 & 335.59 & 7.46 & 12.48 \\
313 & 348.33 & & 16.75 \\
318 & 358.33 & & 20.10 \\
\hline
\end{tabular}

adsorbate studied probably due to enhanced solutesorbent interactions of dipolar nature.

(iii) Increase in the value of "ln $b$ " indicate that the rate of adsorption is much higher than the rate of desorption.

(iv) The 2, 4-D adsorption by GAC is a complex and is probably a combination of external mass transfer, intraparticle diffusion, and sorption process. Thermodynamic constants were also evaluated using equilibrium constants changing with temperature.

(v) The negative value of $\Delta G^{0}$ indicated the spontaneity and the positive values of $\Delta H^{0}$ and $\Delta S^{0}$ showed the endothermic nature and increase in disorder of 2, 4$\mathrm{D}$ adsorption, respectively.

(vi) Energy of activation of adsorption indicates the physical nature of the process.

(vii) The kinetics of adsorption is an activation process that is as the temperature of system increases the rate of the removal of adsorbate increases whereas adsorption capacity decreases.

(viii) Thus as the temperature of the system increases, the rate of adsorption increases.

\section{Nomenclature}

$b: \quad$ Langmuirconstant

C: concentration of the adsorbate in liquid

phase $(\mathrm{mol} / \mathrm{L})$

$C_{0}: \quad$ Initial concentration of the adsorbate

$(\mathrm{mol} / \mathrm{L})$

$C_{e}: \quad$ Equilibrium concentration of the adsorbate $(\mathrm{mol} / \mathrm{L})$

$E_{a}: \quad$ Energy of activation $(\mathrm{kJ} / \mathrm{mol})$

$\Delta G^{0}:$ Standard free energy of adsorption $(\mathrm{kJ} / \mathrm{mol})$

$\Delta H^{0}:$ Standard enthalpy of adsorption $(\mathrm{kJ} / \mathrm{mol})$

$\Delta S^{0}:$ Standard entropy change of adsorption $\left(\mathrm{JK}^{-1} \mathrm{~mol}^{-1}\right)$

$k_{a}$ : Adsorption rate constant $\left(\mathrm{min}^{-1}\right)$

$k_{d}$ : Desorption rate constant $\left(\mathrm{min}^{-1}\right)$

$Q_{0}:$ Adsorbent monolayer capacity $(\mathrm{mol} / \mathrm{g})$

$Q_{e}:$ Adsorbent phase concentration at equilibrium $(\mathrm{mol} / \mathrm{g})$

$R: \quad$ Universal gas constant $\left(\mathrm{JK}^{-1} \mathrm{~mol}^{-1}\right)$

$T: \quad$ Temperature of the system $(\mathrm{K})$.

\section{References}

[1] G. Tchobanoglous, Ed., Wastewater Engineering Treatment, Disposal and Reuse, McGraw-Hill, New York, NY, USA, 1991.

[2] J. W. Weber Jr., Ed., Physicochemical Processes, John Wiley \& Sons, New York, NY, USA, 1972.

[3] G. Rexwinkel, B. B. M. Heesink, and W. P. M. van Swaaij, "Adsorption of halogenated hydrocarbons from aqueous solutions by wetted and nonwetted hydrophobic and hydrophilic sorbents: equilibria," Journal of Chemical and Engineering Data, vol. 44, no. 6, pp. 1139-1145, 1999.

[4] J. S. Zogoroski, Adsorption of phenol onto granular activated carbon from aqueous solution [Ph.D. thesis], Departement of Environmental Science, Rutgers University, New Brunswick, Canada, 2001.

[5] J. L. Sotelo, G. Ovejero, J. A. Delgado, and I. Martínez, "Comparison of adsorption equilibrium and kinetics of four chlorinated organics from water onto GAC," Water Research, vol. 36, pp. 599-608, 2002.

[6] C.-T. Hsieh and H. Teng, "Influence of mesopore volume and adsorbate size on adsorption capacities of activated carbons in aqueous solutions," Carbon, vol. 38, no. 6, pp. 863-869, 2000.

[7] N. Kannan and M. M. Sundaram, "Kinetics and mechanism of removal of methylene blue by adsorption on various carbons: a comparative study," Dyes and Pigments, vol. 51, no. 1, pp. 25-40, 2001.

[8] D. Mohan and S. Chander, "Single component and multicomponent adsorption of metal ions by activated carbons," Colloids and Surfaces A, vol. 177, no. 2-3, pp. 183-196, 2001.

[9] Z. Aksu and J. Yener, "The usage of dried activated sludge and fly ash wastes in phenol biosorption/adsorption: comparison with granular activated carbon," Journal of Environmental Science and Health, vol. 34, no. 9, pp. 1777-1796, 1999.

[10] D. Mohan, V. K. Gupta, S. K. Srivastava, and S. Chander, "Kinetics of mercury adsorption from wastewater using activated carbon derived from fertilizer waste," Colloids and Surfaces A, vol. 177, no. 2-3, pp. 169-181, 2001.

[11] J. P. Chen and M. Lin, "Equilibrium and kinetics of metal ion adsorption onto a commercial H-type granular activated carbon: experimental and modeling studies," Water Research, vol. 35, no. 10, pp. 2385-2394, 2001.

[12] M. O. Corapcioglu and C. P. Huang, "The adsorption of heavy metals onto hydrous activated carbon," Water Research, vol. 21, no. 9, pp. 1031-1044, 1987.

[13] A. Shukla, Y. H. Zhang, P. Dubey, J. L. Margrave, and S. S. Shukla, "The role of sawdust in the removal of unwanted materials from water," Journal of Hazardous Materials, vol. 95, no. 1-2, pp. 137-152, 2002.

[14] G. Newcombe, M. Drikas, and R. Hayes, "Influence of characterised natural organic material on activated carbon adsorption: II. Effect on pore volume distribution and adsorption of 2-methylisoborneol," Water Research, vol. 31, no. 5, pp. 1065-1073, 1997.

[15] S. H. Lin, "Adsorption of disperse dye by powdered activated carbon," Journal of Chemical Technology and Biotechnology, vol. 57, no. 4, pp. 387-391, 1993.

[16] M. Sankar, G. Sekaran, S. Sadulla, and T. Ramasami, "Removal of diazo and triphenylmethane dyes from aqueous solutions through an adsorption process," Journal of Chemical Technology and Biotechnology, vol. 74, no. 4, pp. 337-344, 1999.

[17] C. Hsieh and H. Teng, Carbon, vol. 38, no. 6, pp. 863-869, 2000. 
[18] H. Tamai, T. Kakii, Y. Hirota, T. Kumamoto, and H. Yasuda, "Synthesis of extremely large mesoporous activated carbon and its unique adsorption for giant molecules," Chemistry of Materials, vol. 8, no. 2, pp. 454-462, 1996.

[19] E. Tütem, R. Apak, and C. F. Ünal, "Adsorptive removal of chlorophenols from water by bituminous shale," Water Research, vol. 32, no. 8, pp. 2315-2324, 1998.

[20] Z. Aksu and E. Kabasakal, "Batch adsorption of 2, 4dichlorophenoxy-acetic acid (2, 4-D) from aqueous solution by granular activated carbon," Separation and Purification Technology, vol. 35, no. 3, pp. 223-240, 2004.

[21] I. Langmuir, "The adsorption of gases on plane surfaces of glass, mica and platinum," Journal of the American Chemical Society, vol. 40, no. 9, pp. 1361-1403, 1918.

[22] K. R. Hall, L. C. Eagleton, A. Acrivos, and T. Vermeulen, "Pore- and solid-diffusion kinetics in fixed-bed adsorption under constant-pattern conditions," Industrial and Engineering Chemistry Fundamentals, vol. 5, no. 2, pp. 212-223, 1966.

[23] S. Susarla, G. V. Bhaskar, and S. M. Bhamidimarri Rao, "Adsorption-desorption characteristics of some phenoxyacetic acids and chlorophenols in a volcanic soil I. Equilibrium and kinetics," Environmental Technology, vol. 14, no. 2, pp. 159-166, 1993.

[24] M. Belmouden, A. Assabbane, and Y. A. Ichou, "Removal of 2.4-dichloro phenoxyacetic acid from aqueous solution by adsorption on activated carbon. A kinetic study," Annales de Chimie Science des Matériaux, vol. 26, no. 2, pp. 79-85, 2001. 

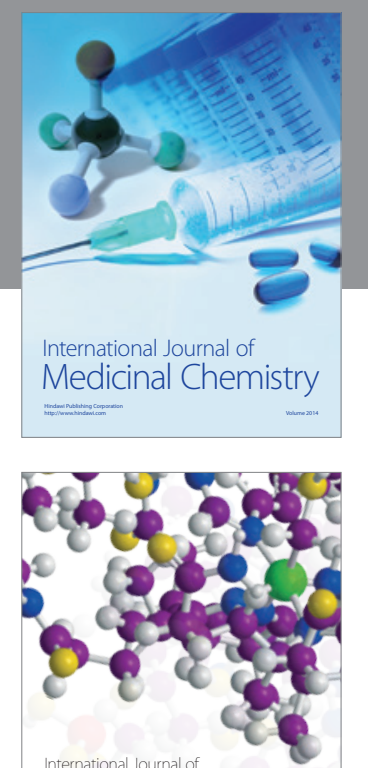

\section{Carbohydrate} Chemistry

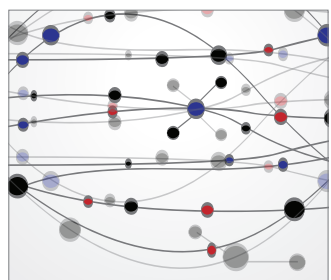

The Scientific World Journal
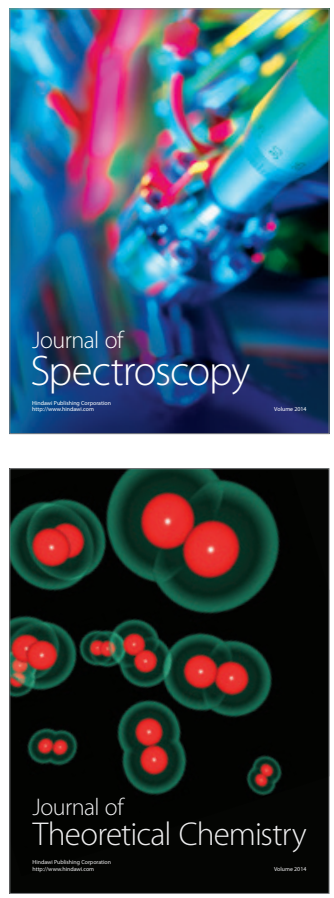
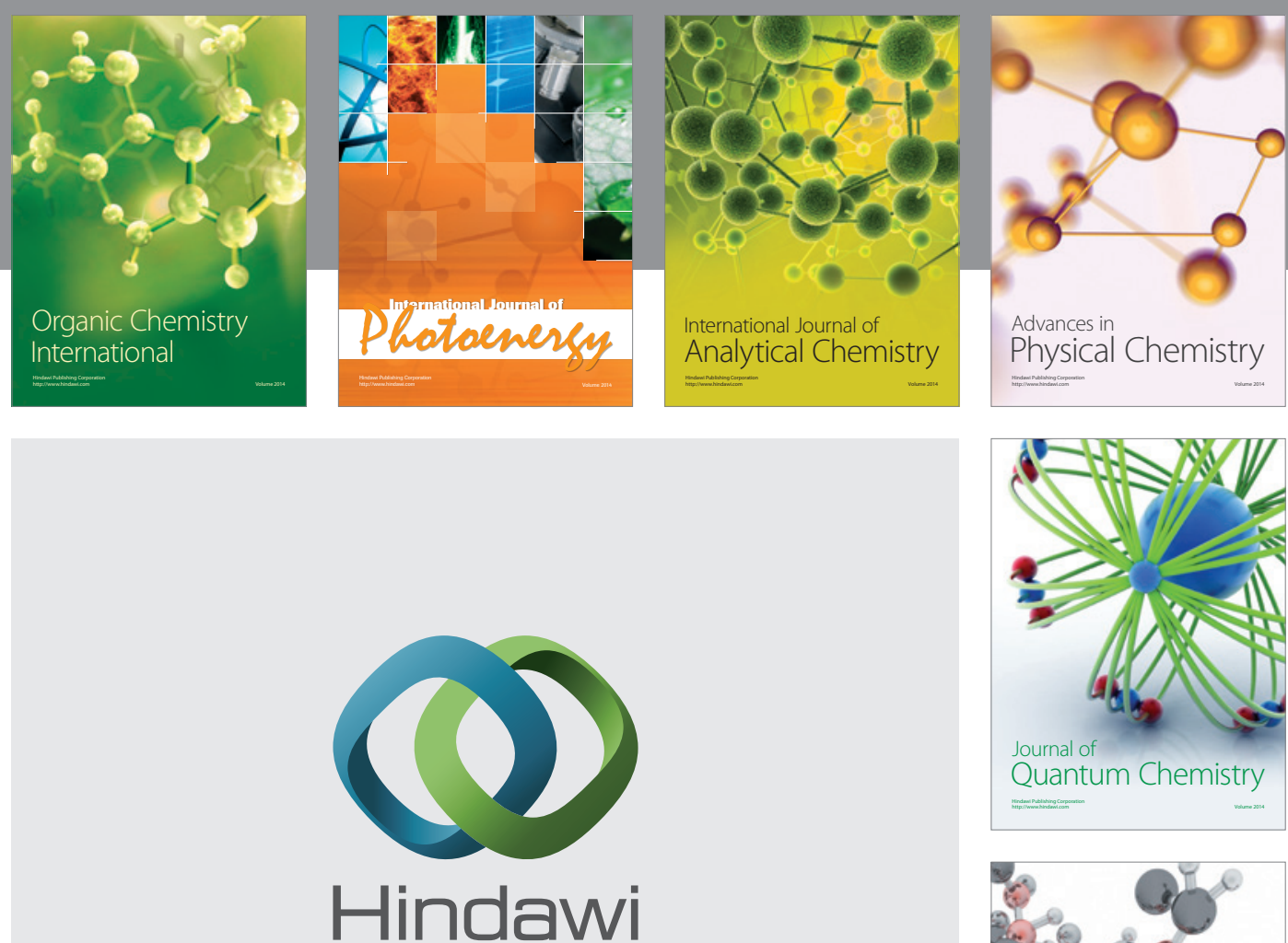

Submit your manuscripts at

http://www.hindawi.com

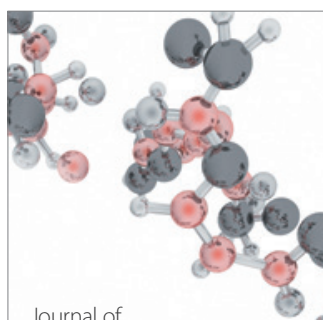

Analytical Methods

in Chemistry

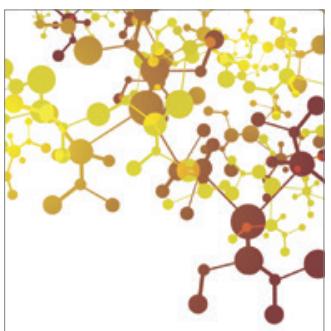

Journal of

Applied Chemistry

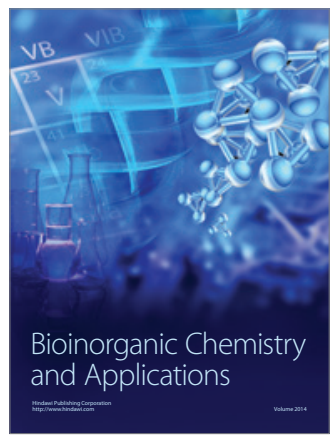

Inorganic Chemistry
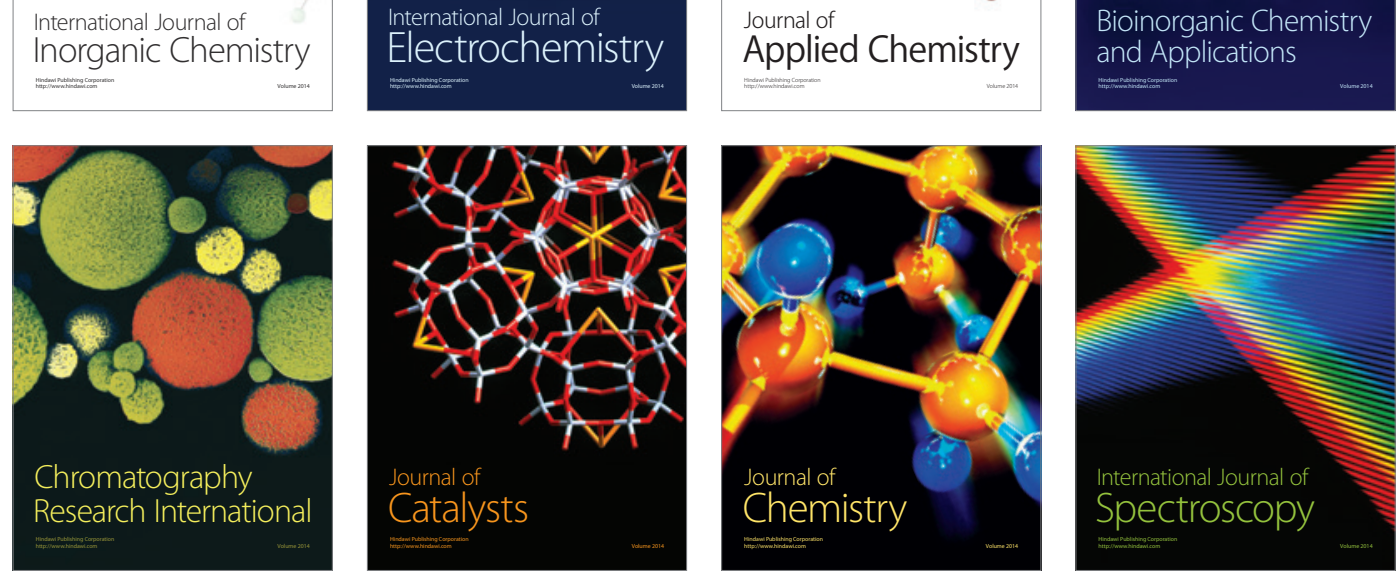